(2) Open Access Full Text Article

\title{
Femtosecond-Assisted Laser in situ
}

\section{Keratomileusis with de novo Flap Creation}

Following Previous Microkeratome Laser in situ

Keratomileusis

\author{
Sloan W Rush ${ }^{1,2}$ \\ Ryan B Rush (D) ${ }^{1-3}$ \\ 'Panhandle Eye Group, Amarillo, TX, \\ 79106, USA; ${ }^{2}$ Department of Surgery, \\ Texas Tech University Health Science \\ Center, Amarillo, TX, 79I06, USA; \\ ${ }^{3}$ Southwest Retina Specialists, Amarillo, \\ TX, 79106, USA
}

Purpose: To report the outcomes of laser in situ keratomileusis (LASIK) in patients with previous microkeratome LASIK using a femtosecond laser platform to create a de novo flap. Methods: The charts of 17 patients that underwent femtosecond-assisted LASIK with de novo flap creation for consecutive refractive error following previous microkeratome LASIK were retrospectively reviewed at a single private practice institution. The baseline characteristics, intraoperative findings and postoperative outcomes were analyzed.

Results: All 17 eyes underwent femtosecond-assisted LASIK with de novo flap creation without significant intraoperative or postoperative complications. Uncorrected visual acuity improved postoperatively $(\mathrm{p}<0.0001)$ and remained stable at 6 months follow-up. None of the subjects lost any lines of best spectacle corrected visual acuity or developed epithelial ingrowth during the postoperative period.

Conclusion: The femtosecond laser technique described in this report can provide a safe and effective method to deliver LASIK following previous microkeratome LASIK. Future investigations are required to further validate the findings in this study.

Keywords: LASIK, cornea, optical coherence tomography

\section{Introduction}

Residual and consecutive refractive error after laser in situ keratomileusis (LASIK) is a relatively common occurrence. ${ }^{1,2}$ The incidence of further refractive surgery has been reported to be as low as $0.18 \%$ but as high as $9.4 \%$, depending upon length of followup. $^{3-5}$ Under these circumstances, there are a variety of retreatment options available to refractive surgeons. ${ }^{6}$ Several reports have described techniques for re-lifting a previous LASIK flap with repeat excimer laser treatment and consecutive photorefractive keratectomy (PRK). ${ }^{7,8}$ However, epithelial ingrowth has been reported to occur as low as $2.3 \%$ and as high as $23.3 \%$ following the re-lifting of an old LASIK flap. ${ }^{9,10}$ To address this complication, one group of researchers attempted mechanical microkeratome cutting of a new flap following previous LASIK. ${ }^{11}$ However, other researchers concluded that, in the absence of other alternatives, old LASIK flaps should always be re-lifted (even if 10 years old) due to safety concerns of cutting new flaps with the microkeratome in patients with previous LASIK. ${ }^{12}$ These conclusions were made prior to development of femtosecond lasers. Now with the advancement of femtosecond laser technology, the improved
Correspondence: Ryan B Rush Southwest Retina Specialists, 74II Wallace Blvd, Amarillo, TX, 79106, USA Tel +I $806351-1870$

Email ryan.rush.md@gmail.com 
flap depth precision of femtosecond lasers compared to the microkeratome coupled with enhanced femtosecond laser settings have demonstrated success in other post-refractive surgery circumstances, most recently involving LASIK after previous radial keratotomy. ${ }^{13-15}$ Investigators have recently proposed a novel femtosecond laser technique in which only the side cut is used to assist with the re-lifting of a previous LASIK flap. ${ }^{16,17}$

To our knowledge, there are currently no reports of an effective technique for creating a new flap with the femtosecond laser in patients undergoing repeat LASIK after previous microkeratome LASIK. In this study, we report a consecutive series of post-LASIK patients that underwent repeat LASIK with a new femtosecond-created flap using enhanced femtosecond laser settings on the Wavelight FS200 (Alcon, Fort Worth, TX, USA).

\section{Methods}

The SRS Institutional Review Board (IRB00009122) approved this retrospective, cases series of patients that received femtosecond laser-assisted LASIK using certain femtosecond settings from July 2015 through October 2019 at a single private practice institution in Amarillo, TX. All components of the study adhered to the tenets of the Declaration of Helsinki and were performed in accordance with human research standards and regulations. Informed consent was not required according to the SRS Institutional Review Board guidelines on retrospective studies without patient identifying information (this study has no patient identifying information and is retrospective).

The operative eyes of consecutive patients that underwent femtosecond-assisted LASIK after previous LASIK with new flap creation on the Wavelight FS200 femtosecond laser and the Wavelight EX500 excimer laser platforms (Alcon, Fort Worth, TX, USA) using specific femtosecond laser settings were included. The demographic and preoperative data collected at baseline from each subject included gender, age, uncorrected visual acuity (UCVA), best spectacle corrected visual acuity (BSCVA), manifest refraction spherical equivalent, corneal pachymetry and the number of years elapsed since the subject's previous microkeratome LASIK surgery. Corneal pachymetry was measured by optical coherence tomography (OCT) with the Cirrus HD-OCT (Carl Zeiss Meditec, Inc, Dublin, California, USA). Intraoperative details and any intraoperative or postoperative complication were recorded for each case. The UCVA, BSCVA and refractive measurements were collected postoperatively at
$2( \pm 1)$ weeks, 2 months ( \pm 2 weeks), and $6( \pm 1)$ months follow-up. The JMP 11 software from the SAS Institute (Cary, NC, USA) was used to calculate means and standard deviations. One-way analysis of the variance was used to compare means, and results were considered statistically significant at the alpha $<0.05$ level.

\section{Femtosecond Laser Settings}

Based upon data from previous studies, the femtosecond laser settings for new flap creation in all patients were as follows: Bed Cut Energy $=1.4 \mu \mathrm{J}$, Bed Cut Spot Separation $=6.0 \mu \mathrm{m}$, Bed Cut Line Separation $=6.0 \mu \mathrm{m}$, Side Cut Energy $=0.8 \mu \mathrm{J}$, Side Cut Spot Separation $=5.0 \mu \mathrm{m}$ and Side Cut Line Separation $=3.0 \mu \mathrm{m} .{ }^{14,15}$ A comparison of these settings to the standard manufacturer default flap settings are listed in Table 1.

\section{Surgical Technique}

By default, a $9.0 \mathrm{~mm}$ flap diameter with a $70^{\circ}$ side cut angle and superior hinge was created in each case. It was determined that only patients in which a $9.0 \mathrm{~mm}$ could fit on the outside of the prior microkeratome flap were treated. Patients with microkeratome flaps greater than $8.0 \mathrm{~mm}$ diameters were excluded from the study. The flap depth varied according to the preoperative OCT measurements of the total central corneal thickness and the OCT-identified depth of the previous

Table I Modified Femtosecond LASIK Flap Settings Compared to the Default Manufacturer Settings on the FS200 Femtosecond Laser

\begin{tabular}{|l|c|c|}
\hline $\begin{array}{l}\text { Femtosecond } \\
\text { Laser }\end{array}$ & $\begin{array}{l}\text { Default } \\
\text { Manufacturer } \\
\text { Femtosecond Laser } \\
\text { Flap Settings }\end{array}$ & $\begin{array}{l}\text { Enhanced Post- } \\
\text { LASIK } \\
\text { Femtosecond Laser } \\
\text { Flap Settings }\end{array}$ \\
\hline $\begin{array}{l}\text { Bed Cut Energy } \\
(\mu \mathrm{J})\end{array}$ & 0.8 & 1.4 \\
\hline $\begin{array}{l}\text { Bed Cut Spot } \\
\text { Separation }(\mu \mathrm{m})\end{array}$ & 8.0 & 6.0 \\
\hline $\begin{array}{l}\text { Bed Cut Line } \\
\text { Separation }(\mu \mathrm{m})\end{array}$ & 8.0 & 6.0 \\
\hline $\begin{array}{l}\text { Side Cut Energy } \\
(\mu \mathrm{J})\end{array}$ & 0.8 & 0.8 \\
\hline $\begin{array}{l}\text { Side Cut Spot } \\
\text { Separation }(\mu \mathrm{m})\end{array}$ & 5.0 & 5.0 \\
\hline $\begin{array}{l}\text { Side Cut Line } \\
\text { Separation }(\mu \mathrm{m})\end{array}$ & 3.0 & 3.0 \\
\hline
\end{tabular}


flap for each patient. Patients in which the prior flap could not be identified were ineligible for flap recut and excluded from the study. The target flap depth was selected to be at least 130 microns thick and no closer than 20 microns to the pre-existing flap, yet thinner than that required to leave at minimum 300 microns of anticipated residual stromal bed tissue post repeat excimer laser photoablation. The new femtosecond flap could be either anterior or posterior to the old flap depending on the latter's original depth. A femtosecond flap retractor (Thorlakson Z-LASIK Flap Lifter, Katena Products, Inc, Denville, NJ) was used to open the side cut at an inferior portion of the flap away from the hinge. After establishing an opening into the stromal plane, the side cut dissection was propagated along the inferior flap margin. The inferior portion of the flap was then retracted and inverted. A Merocel (Medtronic, PLC, Minneapolis, MN) fiber-free sponge was used to carefully retract the rest of the flap toward the hinge. The stromal bed thickness was measured by ultrasonic pachymetry (KMI Surgical LTD, Downingtown, PA) immediately after the new flap was lifted but prior to the excimer laser photoablation treatment. After excimer laser photoablation treatment, the flap was repositioned with a blunt tipped 30gauge cannula on syringe with Balanced Salt Solution (Alcon, Inc, Fort Worth, TX).

\section{Results}

There were 17 eyes of 15 subjects that were included in the analysis with a mean follow-up interval of $6.3 \pm 1.1$ months. A summary of the baseline characteristics and demographic features are presented in Table 2. There were no cases in which suction was either lost or could not be obtained, and all flaps were able to be lifted without complication. There were no cases in which the previous microkeratome LASIK flap was dislocated intraoperatively during surgical manipulation of the new flap. The mean intended flap depth for the study population was $158.8 \pm 23.2$ microns with range of 130 to 190 microns with 9 of the flaps $(52.9 \%)$ posterior to the original flap. UCVA significantly improved from the baseline level at 6 months follow-up $(\mathrm{p}<0.0001)$. Postoperative spherical equivalent averaged $-0.06 \pm 0.20$ diopters (D) and UCVA averaged $0.06 \pm 0.08 \log$ MAR at 6 months followup. No refractive shifts or regression $>0.5 \mathrm{D}$ was noted over the course of follow-up, and there were no eyes that lost one or more lines of BSCVA at the final follow-up visit. There were no cases of diffuse lamellar keratitis or epithelial ingrowth. No patients required postoperative re-
Table 2 Baseline Characteristics and Demographic Features of the Study Population

\begin{tabular}{|l|l|}
\hline $\begin{array}{l}\text { Preoperative Characteristics and } \\
\text { Demographics }\end{array}$ & $\begin{array}{l}\text { Means with (Standard } \\
\text { Deviations) }\end{array}$ \\
\hline Age (years) & $\begin{array}{l}52.0(9.8), \text { Range }=32 \text { to } \\
68\end{array}$ \\
\hline Gender & $\begin{array}{l}17.6 \% \text { Male and } 82.4 \% \\
\text { Female }\end{array}$ \\
\hline $\begin{array}{l}\text { Preoperative uncorrected visual acuity } \\
\text { (logMAR) }\end{array}$ & $\begin{array}{l}0.48(0.24), \text { Range }=0.2 \\
\text { to I.0 }\end{array}$ \\
\hline $\begin{array}{l}\text { Preoperative best spectacle corrected } \\
\text { visual acuity (logMAR) }\end{array}$ & $\begin{array}{l}0.02(0.06), \text { Range }=0 \text { to } \\
0.2\end{array}$ \\
\hline $\begin{array}{l}\text { Preoperative Refractive Error Spherical } \\
\text { Equivalent (diopters) }\end{array}$ & $\begin{array}{l}+0.16(1.54), \text { Range }= \\
-3.0 \text { to }+2.1\end{array}$ \\
\hline $\begin{array}{l}\text { Time since Previous LASIK Surgery } \\
\text { (years) }\end{array}$ & $\begin{array}{l}11.5(7.0), \text { Range }=1 \text { to } \\
20\end{array}$ \\
\hline $\begin{array}{l}\text { Optical Coherence Tomography- } \\
\text { measured Preoperative Total Corneal } \\
\text { Thickness (microns) }\end{array}$ & $\begin{array}{l}516.5(35.3), \text { Range }=452 \\
\text { to } 576\end{array}$ \\
\hline
\end{tabular}

floating or re-positioning of the flap. Standard refractive surgery graphs are displayed in Figure 1.

\section{Discussion}

To our knowledge, this is the first case series to report successful use of the femtosecond laser to create a de novo flap in the setting of an existing microkeratome flap. The efficacy and predictability of this technique in terms of visual results shows outcomes comparable to previously reported studies using femtosecond LASIK in otherwise healthy treatment-naïve eyes without history of prior LASIK where $>97 \%$ of all treated eyes achieve postoperative spherical equivalent within $1 \mathrm{D}$ of error from the intended target. ${ }^{18}$ Creating a new flap with the femtosecond laser is an important retreatment modality to have available because not every patient desires or is a good candidate for PRK, and we believe that it lessens the risk of epithelial ingrowth compared to re-lifting the previous microkeratome flap, which has been reported to occur in as few as $2.3 \%$ of as cases but also in up to $23.3 \%$ after flap re-lift. ${ }^{9,10}$ Furthermore, investigators have reported that relifting a previous microkeratome LASIK flap after more than 3 years is an independent risk factor for the development of epithelial ingrowth. ${ }^{9}$ In our experience, patients with consecutive refractive error often present much 

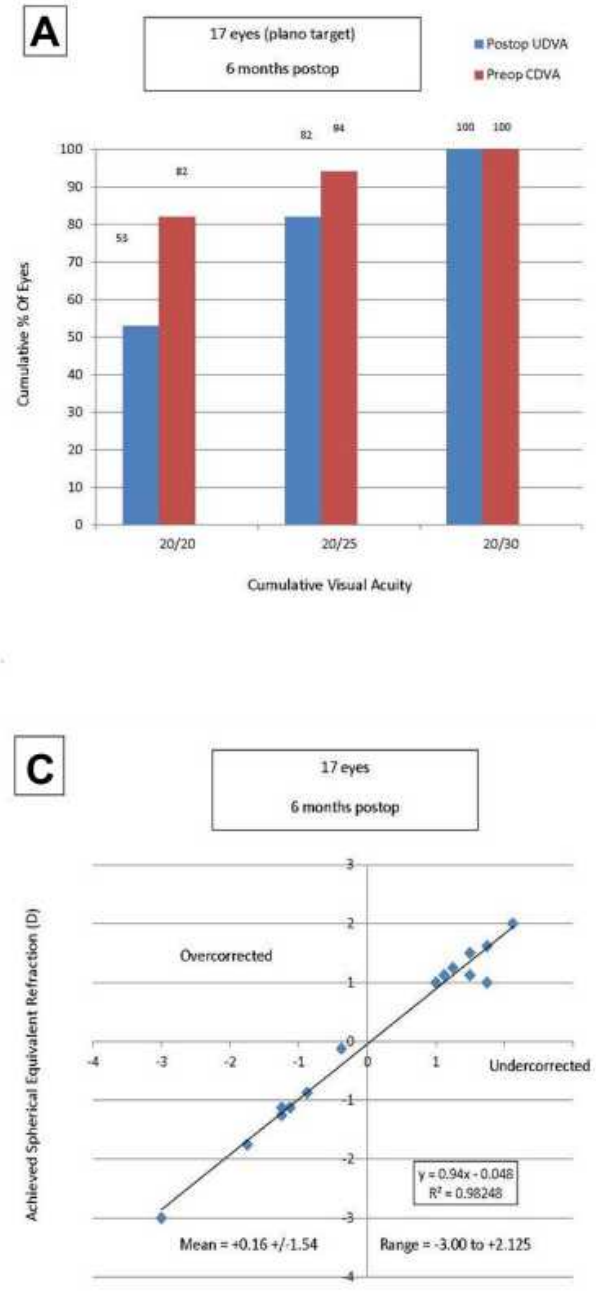

Attempted Spherical Equivalent Refraction (D)

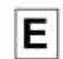

E
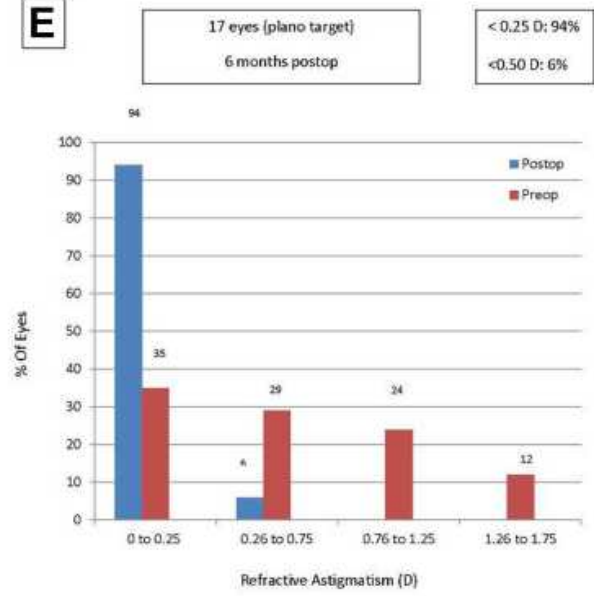

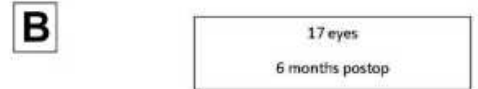

ss

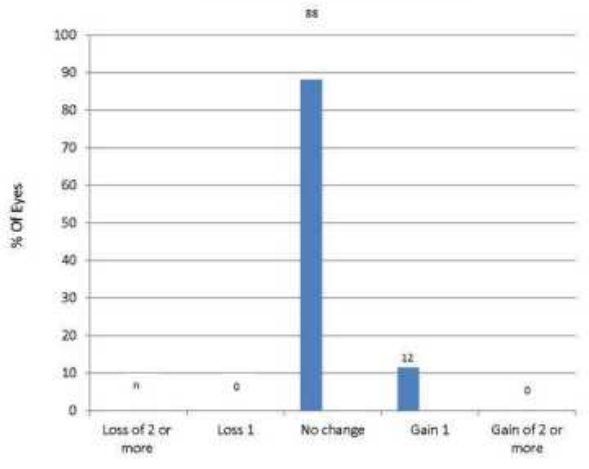

Change in Snellen Lines of COVA
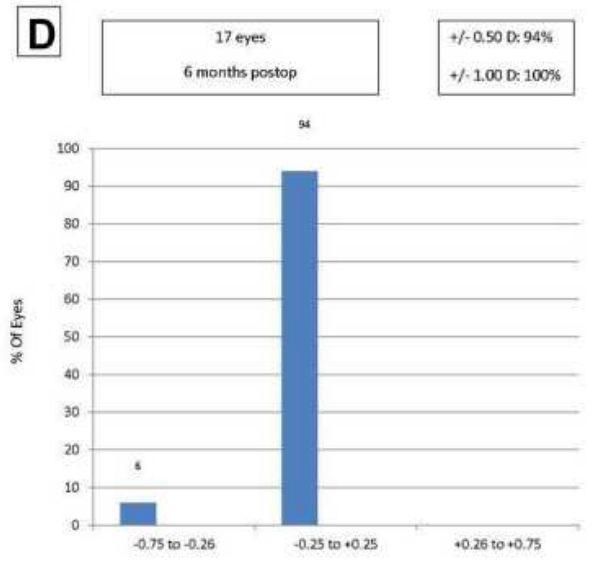

Postoperative Spherical Equivalent Refraction (D)

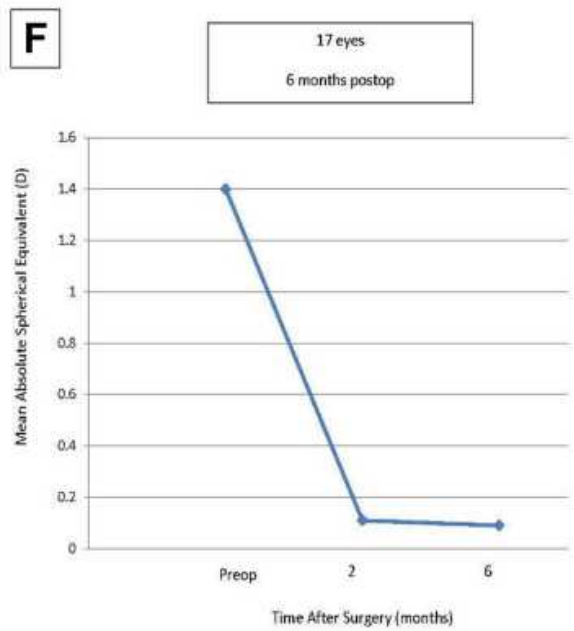

Figure I Standard refractive surgery graphs. (A) Uncorrected distance visual acuity. (B) Change in corrected distance visual acuity. (C) Spherical equivalent attempted vs achieved. (D) Spherical equivalent refractive accuracy. (E) Refractive astigmatism. (F) Stability of spherical equivalent refraction. 
greater than 3 years after LASIK for additional treatment evaluation.

Prior to femtosecond laser technology, devastating complications, including necessity for flap amputation, may occur when cutting and attempting to lift new flaps. ${ }^{19}$ We caution that standard femtosecond laser flap settings used during LASIK leave residual stromal tissue bridges behind that must be manually separated when lifting a newly created flap. We believe that the modified femtosecond laser settings used in this study allow for a safer, less traumatic lifting of the flap on these eyes that already have compromised structural integrity from their previous surgery. The modified femtosecond laser settings used in this study were originally developed in the setting of eyes with previous RK incisions in order to produce a femtosecond laser generated flap that lifted similarly to a mechanical microkeratome generated flap in that it could be lifted with minimal or no resistance. ${ }^{14,15}$ The authors still caution that all eyes with an existing flap are still at increased risk for serious complication regardless of femtosecond laser settings and that extreme caution and gentle stromal dissection must always be used in this scenario.

In our practice, we occasionally encounter patients that have had large previous myopic ablations with microkeratome flap depths measured on OCT of up to 180 microns thick or more. These patients may not have enough residual stroma to safely re-lift the old flap and have further photoablation. Rather than being limited to PRK as the only retreatment option, the technique described in this report allows for retreatment with LASIK by cutting a new, much thinner flap. We believe that OCT technology combined with precise and well-planned femtosecond laser flap depths reduce the risk of treating too deep with ensuing ectasia.

Weaknesses of this study include its retrospective study design, the lack of a control group, the small number of cases, and the relatively short follow-up interval. Future investigations will be necessary to validate the femtosecond-assisted LASIK technique described in this study in subjects with previous microkeratome LASIK and ultimately compare the outcomes to other retreatment modalities such as previous flap re-lifting and PRK.

\section{Abbreviations}

OCT, optical coherence tomography; LASIK, laser in situ keratomileusis; BSCVA, best spectacle-corrected visual acuity; UCVA, uncorrected visual acuity.

\section{Data Sharing Statement}

The datasets used and/or analyzed during the current study are available from the corresponding author on reasonable request.

\section{Declarations}

The study was approved by the SRS Institutional Review Board in accordance with the Ethical Standards laid down in the Declaration of Helsinki.

\section{Author Contributions}

All authors made substantial contributions to conception and design, acquisition of data, or analysis and interpretation of data; took part in drafting the article or revising it critically for important intellectual content; agreed to submit to the current journal; gave final approval of the version to be published; and agree to be accountable for all aspects of the work.

\section{Funding}

There is no funding to report.

\section{Disclosure}

This study was presented at the 2017 ASCRS meeting during a paper session. The authors report no conflicts of interest in this work.

\section{References}

1. Yuen LH, Chan WK, Koh J, et al. A 10-year prospective audit of LASIK outcomes for myopia in 37,932 eyes at a single institution in Asia. Ophthalmology. 2010;117(6):1236-1244. doi:10.1016/j.ophtha.2009.10.042

2. Randleman JB, White AJ Jr, Lynn MJ, et al. Incidence, outcomes, and risk factors for retreatment after wavefront-optimized ablations with PRK and LASIK. J Refract Surg. 2009;25(3):273-276. doi:10.3928/ 1081597X-20090301-06

3. Mimouni M, Vainer I, Shapira Y, et al. Factors predicting the need for retreatment after laser refractive surgery. Cornea. 2016;35(5):607-612. Epub ahead of print. doi:10.1097/ICO.0000000000000795

4. Valdez-García JE, Hernandez-Camarena JC, Martínez-Muñoz R. 3-Year follow-up after Lasik: assessing the risk factors for retreatment. Int Ophthalmol. 2016;36(1):91-96. doi:10.1007/s10792015-0084-4

5. Bragheeth MA, Fares U, Dua HS. Re-treatment after laser in situ keratomileusis for correction of myopia and myopic astigmatism. $\mathrm{Br}$ J Ophthalmol. 2008;92(11):1506-1510. doi:10.1136/bjo.2008.143636

6. Schallhorn SC, Venter JA, Hannan SJ, et al. Flap lift and photorefractive keratectomy enhancements after primary laser in situ keratomileusis using a wavefront-guided ablation profile: refractive and visual outcomes. J Cataract Refract Surg. 2015;41(11):2501-2512. doi:10.1016/j.jcrs.2015.05.031

7. Santhiago MR, Smadja D, Zaleski K, et al. Flap relift for retreatment after femtosecond laser-assisted LASIK. J Refract Surg. 2012;28 (7):482-487. doi:10.3928/1081597X-20120615-02

8. Broderick KM, Sia RK, Ryan DS, et al. Wavefront-optimized surface retreatments of refractive error following previous laser refractive surgery: a Retrospective Study. Eye Vis (Lond). 2016;11(3):3. doi:10.1186/s40662-016-0034-x 
9. Caster AI, Friess DW, Schwendeman FJ. Incidence of epithelial ingrowth in primary and retreatment laser in situ keratomileusis. $J$ Cataract Refract Surg. 2010;36(1):97-101. doi:10.1016/j. jcrs.2009.07.039

10. McAlinden C, Moore JE. Retreatment of residual refractive errors with flap lift laser in situ keratomileusis. Eur J Ophthalmol. 2011;21 (1):5-11. doi:10.5301/EJO.2010.391

11. Davis EA, Hardten DR, Lindstrom M, et al. Lasik enhancements: a comparison of lifting to recutting the flap. Ophthalmology. 2002;109(12):2308-2313. doi:10.1016/S0161-6420(02)01245-9

12. Rubinfeld RS, Hardten DR, Donnenfeld ED, et al. To lift or recut: changing trends in LASIK enhancement. J Cataract Refract Surg. 2003;29(12):2306-2317. doi:10.1016/j.jcrs.2003.08.013

13. Leccisotti A, Fields SV. Femtosecond-assisted laser in situ keratomileusis for consecutive hyperopia after radial keratotomy. J Cataract Refract Surg. 2015;41(8):1594-1601. doi:10.1016/j.jcrs.2015.08.014

14. Rush SW, Rush RB. One-year outcomes of femtosecond laser-assisted LASIK following previous radial keratotomy. $J$ Refract Surg. 2016;32(1):15-19. doi:10.3928/1081597X-20151 207-07
15. Rush SW, Rush RB. Femtosecond laser flap creation for laser in situ keratomileusis in the setting of previous radial keratotomy. Asia Pac J Ophthalmol (Phila). 2015;4(5):283-285. doi:10.1097/APO.000000 0000000131

16. Vaddavalli PK, Yoo SH, Diakonis VF, et al. Femtosecond laser-assisted retreatment for residual refractive errors after laser in situ keratomileusis. $J$ Cataract Refract Surg. 2013;39 (8):1241-1247. doi:10.1016/j.jcrs.2013.03.018

17. Coskunseven E, Kymionis GD, Grentzelos MA, et al. Femtosecond LASIK retreatment using side cutting only. J Refract Surg. 2012;28 (1):37-41. doi:10.3928/1081597X-20110812-01

18. Ang M, Mehta JS, Rosman M, et al. Visual outcomes comparison of 2 femtosecond laser platforms for laser in situ keratomileusis. J Cataract Refract Surg. 2013;39(11):1647-1652. doi:10.1016/j. jers.2013.04.044

19. Domniz Y, Comaish IF, Lawless MA, et al. Recutting the cornea versus lifting the flap: comparison of two enhancement techniques following laser in situ keratomileusis. J Refract Surg. 2001;17 (5):505-510. doi:10.3928/1081-597X-20010901-02
Clinical Ophthalmology

\section{Publish your work in this journal}

Clinical Ophthalmology is an international, peer-reviewed journal covering all subspecialties within ophthalmology. Key topics include: Optometry; Visual science; Pharmacology and drug therapy in eye diseases; Basic Sciences; Primary and Secondary eye care; Patient Safety and Quality of Care Improvements. This journal is indexed on PubMed

\section{Dovepress}

Central and CAS, and is the official journal of The Society of Clinical Ophthalmology (SCO). The manuscript management system is completely online and includes a very quick and fair peer-review system, which is all easy to use. Visit http://www.dovepress.com/ testimonials.php to read real quotes from published authors. 